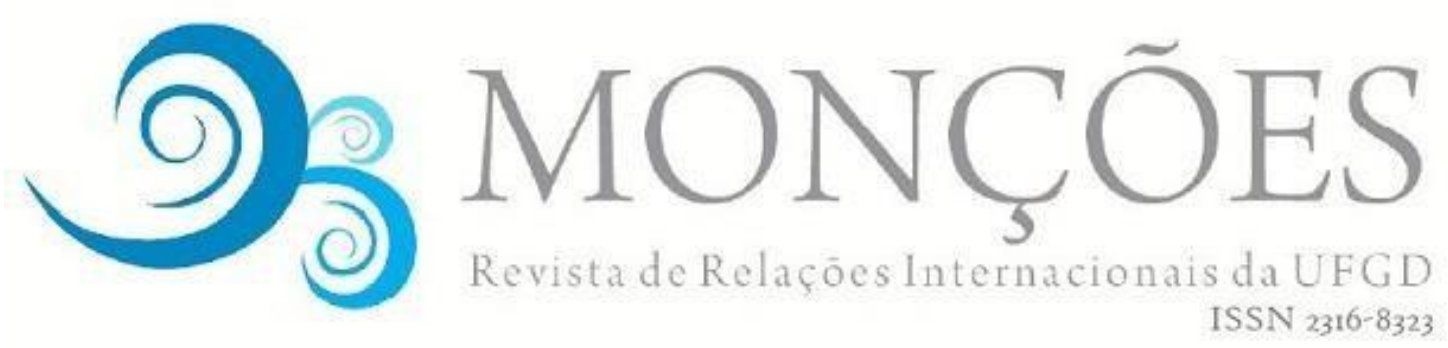

\title{
FEMINISMOS EM TRÂNSITO INTERNACIONAL: A CIRCULAÇÃO DO CONHECIMENTO FEMINISTA ENTRE BRASIL E FRANÇA
}

\author{
ELENA DE OLIVEIRA SCHUCK
}

Professora do Instituto Latino-Americano de Economia, Sociedade e Política (ILAESP) da Universidade Federal da Integração Latino-Americana (UNILA) - Pesquisadora do Núcleo Interdisciplinar de Estudos sobre Mulher e Gênero (NIEM/UFRGS)

\begin{abstract}
RESUMO: Este trabalho pretende estabelecer os marcos teóricos e epistemológicos para a realização de um mapeamento da circulação do conhecimento feminista entre Brasil e França. O período de análise parte da década de 1970, marcada pela criação do Círculo de Mulheres Brasileiras em Paris e pelo início da entrada da teoria feminista francesa no Brasil, chegando à década de 2010, momento caracterizado pela dinamização e globalização das relações de saber e poder. Buscamos identificar as condições históricas, políticas e institucionais que propiciaram interações teóricas feministas entre Brasil e França, a partir da opção analítica da circulação de conhecimento em detrimento da consideração de fluxos unidirecionais França-Brasil. A contribuição deste trabalho opera no sentido de dar visibilidade às trocas teóricas entre os dois países, as quais têm se ampliado por meio de novas pautas de discussão científica e epistemológica, abrangendo a diversidade teórica proveniente do Sul Global e de perspectivas pós-coloniais.
\end{abstract}

PALAVRAS-CHAVE: teorias feministas, circulação de conhecimento, Brasil, França.

\section{FEMINISMS IN INTERNATIONAL TRANSIT: THE CIRCULATION OF FEMINIST KNOWLEDGE BETWEEN BRAZIL AND FRANCE}

ABSTRACT: This paper intends to establish a theoretical and epistemological framework for mapping feminist knowledge circulation between Brazil and France. The period of analysis begins on the 1970s, during the creation of the Circle of Brazilian Women in Paris and when the French feminist theory was introduced in Brazil, going until the 2010's, a moment characterized by the dynamization and globalization of power and knowledge relations. We sought to identify the historical, political, and institutional conditions that favored feminist theoretical interactions between Brazil and France, based on the circulation of knowledge in detriment of unidirectional flows from France to Brazil. The contribution of this paper is to give visibility to theoretical exchanges between the two countries. These exchanges have been expanded through new scientific and epistemological discussion, covering the theoretical diversity from the Global South and from postcolonial perspectives.

KEYWORDS: feminist theories, knowledge circulation, Brazil France. 


\section{Introdução}

Esta proposta nasce do questionamento sobre a gradual visibilidade do pensamento feminista e suas trocas a nível internacional, colocando ênfase nos intercâmbios entre o conhecimento feminista brasileiro e francês. O feminismo é um tema que tem ganhado maior projeção internacional devido às suas particulares formas de pluralização de mobilizações, as quais tratam de questões que afetam pelo menos metade da população mundial.

Em um percurso que compreende a década de 1970 até os dias atuais, percebemos o desenvolvimento heterogêneo dos estudos feministas no cenário acadêmico brasileiro. O que está em discussão, assim, não é um feminismo, no singular, mas diversos feminismos (ALVAREZ, 2014; MENDES, 2008; OLESEN, 2006). Tal diversificação, que se intensifica nas duas primeiras décadas do Século XXI, permite-nos examinar articulações cada vez mais notórias entre reflexões e práticas sócio-políticas. Assistimos, em verdade, a um alargamento das reivindicações sociais em nível global, que engendram questões relativas aos feminismos, às mulheres, a gênero, às diversas formas de dominação e às possibilidades de emancipação. Ainda nessa conjuntura, evidenciam-se as abordagens que postulam uma visão transformadora e crítica do pensamento e da militância feministas, mobilizando conceitos tanto de sexo/gênero, sexualidade/práticas político-sexuais, raça/etnia, nacionalidade, quanto de classe ${ }^{1}$.

A questão central que motiva esta proposta é a compreensão das condições nas quais houve encontros entre o pensamento feminista francês e brasileiro, sob a perspectiva analítica da circulação internacional de ideias. Temos por objetivo determinar os momentos de convergência entre os estudos feministas destes países, desenvolvendo, assim, uma cartografia das trocas teóricas entre as duas regiões desde o período de autonomização do feminismo brasileiro, na década de 1970, até os dias de hoje. Buscamos identificar as condições históricas, políticas e institucionais que propiciaram interações teóricas feministas entre Brasil e França, as quais podem

\footnotetext{
1 Jules Falquet e Ochy Curiel (2014), em um esforço de difundir o trabalho de feministas latinas e caribenhas através de traduções, adicionam os conceitos de práticas político-sexuais e nacionalidades às análises interseccionais de gênero, raça e classe.
} 
ser distinguidas em dois momentos: entre os anos 1970 e 1985, período em que se observa nos debates acadêmicos feministas um fluxo teórico que parte da França em direção ao Brasil; e dos anos 2000 a 2015, período no qual observamos uma reconfiguração dos fluxos teóricos feministas, quando o pensamento feminista francês se aproxima das ideias feministas do Sul Global2, e o pensamento feminista brasileiro dinamiza-se, diversificando suas trocas teóricas com vizinhos da América Latina e com os Estados Unidos.

Para cumprir com o objetivo de mapeamento da circulação de conhecimento feminista, apresentamos uma proposta metodológica a qual consideramos compatível com este exercício analítico inicial. A metodologia apoia-se em abordagens epistemológicas feministas e se adequa ao propósito de mapeamento dos trajetos internacionais do pensamento feminista no eixo Brasil-França. Realizamos um estudo empírico que compreendeu a consulta a revistas científicas brasileiras e francesas, para análise comparada de conteúdo envolvendo autorias e temáticas que dialoguem para além das fronteiras linguísticas, geográficas e culturais.

O desenvolvimento da reflexão aqui exposta envolve quatro partes: em um primeiro momento, apresentamos a trajetória do pensamento feminista, isto é, tratamos de abordar a teoria feminista nos marcos do campo do conhecimento. $\mathrm{Na}$ segunda parte, a partir das retrospectivas históricas e epistemológicas do campo de estudo feminista, apresentamos o conceito de travelling theories de Edward Said, combinado a outras abordagens feministas sobre circulação de conhecimento. Esta parte tem por objetivo reunir suporte teórico e metodológico para o mapeamento da movimentação internacional de ideias feministas entre Brasil e França. Na terceira parte, apresentamos algumas interações identificadas entre os campos de estudos

\footnotetext{
${ }^{2}$ Tomamos emprestado de Boaventura Sousa Santos (2010) a concepção de Sul Global, cuja ideia central é tratar do Sul metaforicamente enquanto campo de desafios epistêmicos, os quais procuram reparar os danos e impactos historicamente causados pelo capitalismo na sua relação colonial com o mundo. A concepção de Sul em parte sobrepõe-se com o Sul Geográfico, o conjunto de países e regiões do mundo que foram submetidos ao colonialismo europeu e que, salvo exceções, não atingiram níveis de desenvolvimento econômico semelhantes ao do Norte Global (Europa e América do Norte). A sobreposição não é total, pois o Norte geográfico inclui grupos sociais muito vastos que também foram sujeitos à dominação capitalista e colonial, tal qual a região do Magreb, colonizada pela França, e também a população imigrante, magrebina e muçulmana francesa.
} 
feministas brasileiro e francês com base na literatura específica. Por fim, na quarta parte, iniciamos o mapeamento da circulação a partir dos os pilares teóricos desenvolvidos ao longo deste artigo. Nesta última etapa, cartografamos o fluxo de teorias feministas entre Brasil e França a partir da análise de conteúdo de periódicos científicos sobre gênero e feminismo. Vislumbramos expandir o entendimento sobre a formação e o trânsito de ideias na agenda de pesquisa feminista e contribuir para a compreensão dos rumos dinâmicos e transfronteiriços dos debates feministas presentes na comunidade científica internacional da atualidade.

\section{Pensamento feminista e campo científico}

O pensamento feminista deriva das reflexões acerca da desigualdade entre homens e mulheres presente em grande parte das sociedades, recusando a afirmação de que tal desigualdade seria apenas um reflexo da natureza diferenciada de dois sexos, necessária para a sobrevivência da espécie humana. A recusa da tese da diferença sexual implica o desenvolvimento de uma crítica ampla do mundo social. Tal crítica aponta para a reprodução de assimetrias que tolhem a agência de muitos integrantes do mundo social e reforçam as diversas opressões às mulheres (MIGUEL, 2014). Desse modo, o pensamento feminista pode ser conceituado enquanto fruto da elaboração sucessiva de experiências, debates, e polêmicas se fazendo presente tanto na ação quanto na reflexão feminista, embora sujeito a questionamentos quanto a sua legitimidade na prática e na teoria. Face à suposta ilegitimidade do interesse conceitual do feminismo, a reflexão intelectual constrói-se, necessariamente, apoiada na prática, seja ela um acontecimento ou um problema (FRAISSE, 2011). De outro modo, seria fácil reduzir o pensamento feminista a uma mera conviç̧ão.

Embora com espaço reduzido nos debates sobre o político e a democracia, o feminismo é provavelmente uma das correntes intelectuais da modernidade e da filosofia política que mais provocou mudanças sociais ao denunciar as desigualdades, a opressão e os mecanismos de dominação masculina (VALCÁRCEL, 2012, p.15; MACKENZIE, 2011, p.26, p.141; MIGUEL, 2014, p. 17). Conforme as formas de dominação foram se tornando complexas e exigindo ferramentas mais sofisticadas 
para entendê-las, o pensamento feminista foi se constituindo enquanto campo de conhecimento composto por teorias capazes de auxiliar na compreensão da reprodução das desigualdades de gênero.

Entendemos que o pensamento feminista deva ser colocado no plural, pois, conforme a associação de onde se extraem os conceitos para serem criticados, destruídos ou reconstruídos, dá-se a origem às diferentes formas de pensar das teóricas feministas. As associações ora pendem para um feminismo igualitário, com vertentes em disputa conceitual sobre preceitos liberais e marxistas, ora pendem para um feminismo da diferença, cujas vertentes aproximam-se dos pós-estruturalistas e dos pós-modernistas, recebendo influência do pensamento de Foucault, Derrida, Lacan e demais intelectuais deste campo teórico. Ademais, a dinamização dos fluxos globais de pensamento permite maior interface e diálogo entre abordagens feministas de matriz no Norte Global, com as pautas trazidas por feminismos diversos do Sul Global. As abordagens do feminismo indígena, islâmico, negro, pós-colonial, decolonial, queer ou trans, por tratarem de grupos de pessoas à margem dentro do próprio feminismo, apontam a necessidade de repensar a polarização entre 0 feminismo da igualdade e o feminismo da diferença em um mundo intercultural e interseccionado por múltiplas opressões de gênero, classe, geopolítica, raça, cultura, religião, e sexualidade.

A base a partir da qual este artigo se desenvolve é a ideia de que existe uma teoria política feminista autônoma, isto é, uma contribuição teórica que independe de outras escolas do pensamento político e, mais do que isso, que também há uma epistemologia feminista própria. Margareth Rago (1998) sublinhou a necessidade de aprofundar um debate brasileiro sobre a pertinência de uma teoria do conhecimento feminista e junto a ela outras autoras brasileiras avançaram nesta direção. Há o esforço em demonstrar como a ótica feminista contribui para transformar a produção científica, muito especialmente no campo das ciências sociais, empregando não apenas um arcabouço conceitual diferenciado, como também redescobrindo temas de pesquisa e empregando metodologias de forma a reduzir o caráter instrumental de uma concepção de ciência criada em berço positivista. Destacando o campo da ciência política, Flávia Biroli e Luis Felipe Miguel (2012) igualmente valorizaram a 
especificidade da contribuição feminista na análise especialmente das relações de poder dominantes na sociedade.

Primeiramente as críticas feministas se desenvolveram por meio de questões contextuais como a discriminação das mulheres na ciência, a hierarquia masculina predominante nos principais espaços acadêmicos das diferentes áreas, o uso da tecnologia para reforçar a submissão social das mulheres, entre outras. Entretanto, logo esses temas avançaram em direção a questionamentos sobre as bases do pensamento ocidental contemporâneo, isto é, colocaram em tela de juízo não apenas as conclusões apresentadas pela ciência moderna, mas também seus procedimentos e fundamentos (HARDING, 1993).

Virginia Olesen (2010), de maneira semelhante, sublinha que a partir do final da década de sessenta a pesquisa feminista foi se complexificando. Se em uma primeira fase abundaram as críticas sobre o caráter de gênero das disciplinas acadêmicas, das instituições científicas e, inclusive, da falta de atenção da ciência diante da discriminação da mulher, numa segunda fase o foco foi lançado sobre a necessidade de desenvolver uma epistemologia crítica. $O$ debate que passou a valorizar, entre outras coisas, o reconhecimento da diferenciação entre os indivíduos envolvidos com as pesquisas, levou ao questionamento da ideia de mulher enquanto um sujeito universal, assim como às próprias características das pesquisadoras e suas condições de trabalho.

O debate sobre uma epistemologia feminista incentivou o surgimento de um conjunto de abordagens que postulam uma visão emancipadora e transformadora do feminismo, com o uso dos conceitos tanto de sexo/gênero, raça/etnia quanto de classe. Várias autoras, ao combinar todas estas dimensões, contribuem para a compreensão dos fenômenos que ocorrem com as mulheres em nível mundial, abarcando vários fatores que contribuem, em diferentes graus, para as condições de opressão e vulnerabilidade das mulheres ${ }^{3}$. Tais condições são identificadas a partir do pensamento crítico que aponta as causas da discriminação das mulheres na

\footnotetext{
${ }^{3}$ Para citar alguns exemplos, neste campo identificamos autoras como Nancy Fraser, Iris Young, Célia Amorós, Amélia Valcárcel e Maria Luisa Femenías que colaboram com uma visão ampla do feminismo, estando atentas às ciladas presentes no campo das teorias.
} 
sociedade: a concepção de mundo androcêntrica (FRASER, 1995), ou seja, a construção autoritária de normas sociais, políticas e econômicas que privilegiam traços associados à masculinidade ${ }^{4}$.

Nessa direção, Magdalena Valdivieso (2014) ressalta o papel crítico precursor do feminismo nos processos de desconstrução e confrontação dos saberes patriarcais hegemônicos ancorados na concepção androcêntrica de mundo:

[...] ao resistir à homogeneização, ao questionar a universalidade e ao constituir-se, desde a sua criação, em um espaço de pensamento e práticas questionadoras e alternativas éticas ao modelo político -cultural dominante, desenvolvida a partir de lugares subalternizados e de posições marginais em espaços tradicionais. A teoria feminista também tem sido uma das principais fontes de mudança cultural que permitiu pensar a complexidade da construção social e cultural da subjetividade, ao recusar o sujeito humano abstrato e universal e revelar uma sujeita concreta, feminina e subordinada (Valdivieso, 2014, p.30., tradução nossa ${ }^{5}$ ).

No caso latino-americano é necessário ainda destacar a importância do conceito de patriarcado e sua relação com o ideário pós-colonialista. Como, segundo algumas autoras, o conceito de gênero não dá conta da diversidade do 'ser mulher' na América Latina é preciso construir um complexo de conceitos articulando patriarcado, sexo, gênero, classe e, especialmente, a relação raça/etnia. Entendemos aqui a importância do pensamento feminista para questionar a normatização patriarcal, compreender, descrever ou explicar a opressão e exploração das mulheres

\footnotetext{
${ }^{4}$ Nancy Fraser (1995) aponta as injustiças de gênero como sendo uma combinação de injustiças econômicas/materiais e culturais/simbólica resultantes da institucionalização de normas culturais sexistas e androcêntricas pelo Estado e pela economia. As desvantagens econômicas colocadas às mulheres restringem sua voz, limitando uma igual participação na esfera pública, na construção de padrões culturais e na vida cotidiana, o que gera um circula vicioso de subordinação. Fraser propõe a articulação do reconhecimento e da redistribuição, fazendo questão de enfatizar a definição do conceito de androcentrismo, o qual constitui a causa dos problemas apontados.

${ }^{5}$ Trecho original em espanhol: "al resistirse a la homogenización, al cuestionar la universalidad y al constituirse, desde sus inicios, en un espacio de pensamiento y prácticas cuestionadoras y alternativas éticas al modelo político-cultural dominante, elaboradas desde lugares subalternizados y desde posiciones marginales en espacios tradicionales. La teoría feminista ha sido también una de las principales fuentes del giro cultural que ha permitido pensar la complejidad de la construcción social y cultural de la subjetividad, al negar el sujeto humano abstracto y universal y revelar una sujeta concreta, femenina y subordinada" (Valdivieso, 2014, p.30).
} 
e lutar pela sua superação, assim como identificar quais estruturas sociais e processos de interação mantêm a dominação masculina e a subordinação feminina. As análises teóricas feministas têm, por consequência, a prática política como objeto.

Para Flavia Biroli (2012) o processo quase à margem - senão à margem - das teóricas feministas que buscam a constituição de uma epistemologia feminista, nitidamente imbricada com as teorias críticas, visa uma reconstrução crítica da tradição intelectual principalmente advinda do ocidente. Neste sentido, Biroli destaca dois momentos de afirmação de um lócus para a reflexão feminista como um corpo teórico:

\begin{abstract}
Se em algum momento foi válida a inspirada caracterização de Linda Singer, da teórica feminista como "Bandita", uma bandoleira que passeia pela história da filosofia, saqueando aquilo que pode ser aproveitado da obra dos pensadores homens (apud Young, 1997, p. 23), hoje certamente não é mais assim. Há tradições feministas que estabelecem o enquadramento de suas questões, com um corpo de debates e de conceitos com crescente abrangência e uma sofisticação que, não raras vezes, chega à beira do hermetismo. Tal como aconteceu com o marxismo, a partir sobretudo da segunda metade do século passado, o desafio é não permitir que essa complexidade descole o pensamento sobre o mundo das práticas sociais transformadoras que o feminismo, desde sua origem, se propõe a impulsionar.

No campo da teoria política, o aporte do feminismo se constitui, desde os anos 1980, no principal elemento de renovação e no grande desafio às correntes previamente estabelecidas. Não se trata de um corpo teórico "alternativo" ou da introdução da categoria "gênero" como adendo às preocupações tradicionais da disciplina. O feminismo deslocou os debates centrais da teoria política, recolocando os termos em que é possível discutir, hoje, questões como a democracia, a representação, a justiça, a esfera pública, a sociedade civil, a autonomia, a igualdade, a cidadania ou o Estado (BIROLI, 2012, p.8).
\end{abstract}

A articulação entre os vários lócus de atuação no trabalho de difusão do pensamento feminista faz-se, portanto, necessária para que a sociedade confira valor ao feminismo enquanto sujeito de construção da democracia e do conhecimento. Assim, o desafio do campo epistemológico permanece central nas reflexões feministas em função da necessidade de afirmar, recorrentemente, sua existência na reflexão teórica e na construção do conhecimento científico.

Nesta seção abordamos as contribuições teóricas feministas, enfatizando sua independência de outras escolas do pensamento político e também sua autonomia, a 
qual reverbera na existência de uma epistemologia feminista própria. Buscamos congregar elementos que caracterizam o campo científico feminista, a fim de possibilitar a análise das dos fluxos internacionais de conhecimento feminista.

\section{A circulação de ideias feministas}

No intuito de construir o embasamento teórico para a elaboração de um mapeamento da circulação de ideias feministas entre os campos de pesquisa brasileiro e francês, buscamos nesta seção discutir abordagens que dimensionem a circulação global de conhecimento feminista. A priorização de uma perspectiva que considere os diversos fluxos teóricos das duas regiões em detrimento de fluxos unidirecionais é fruto de reflexões epistemológicas sobre os processos de construção de conhecimento consoante às críticas ao colonialismo, à relação saber-poder desigual Norte/Sul, bem como à dominação epistemológica eurocentrada.

O pensamento descolonizador, conforme aponta Silvia Rivera Cusicanqui (2010), emerge no conjunto interligado e autônomo da cultura, teoria, epistemologia e política de Estado no Sul Global. O desafio desta nova autonomia consiste em construir laços Sul-Sul que permitam romper com os triângulos sem base da política e da academia do Norte. Para a autora, esta autonomia depende da construção de uma ciência própria, baseada no diálogo com os países vizinhos, com o fortalecimento de laços com as correntes teóricas da Ásia e de África para o enfrentamento dos projetos epistemológicos do Norte.

Chandra Mohanty (1988) destaca a importância do olhar atento e crítico aos colonialismos discursivos, os quais podem ser identificados nos escritos ocidentais (dos EUA e Europa) sobre mulheres do terceiro mundo, ou na terminologia mais recente, mulheres do Sul global. Há de se levar em conta, portanto, o contexto hegemônico global do conhecimento ocidental no qual a produção, publicação, distribuição e consumo de ideias e informações tem efeitos políticos inegáveis implicações para além do feminismo imediato ou de um público leitor específico. Se a representação dominante de um feminismo ocidental ainda se faz vigente, há de se 
reiterar um posicionamento situado e crítico com relação à investigação científica em torno da circulação de conhecimento feminista entre o Sul e o Norte global.

Para pensar a circulação de ideias feministas entre França e Brasil no período que vai de 1970 a 2015 apoiamo-nos nas travelling theories ou "teorias viajantes" de Edward Said (1983), considerando também a possível existência de uma triangulação maior, constituída por América Latina, Estados Unidos e França. Said sustenta que as ideias e teorias viajam de pessoa a pessoa, de situação a situação, de uma época a outra. Essa circulação de ideias alimenta a vida cultural e intelectual, e mesmo assumindo um formato de influência conhecida/visível ou inconsciente, de empréstimo criativo ou apropriação, o movimento de ideias e teorias é um fato da vida e uma condição útil à atividade intelectual. Implicações ainda maiores estão em jogo quando tais ideias viajam de uma cultura a outra (LUSTE BOULBINA, 2013).

Para Said, o movimento de ideias entre culturas diferentes, como por exemplo as ideias de transcendência do oriente que foram levadas à Europa no início do século XIX, nunca está desimpedido. Ele envolve necessariamente processos de representação e institucionalização diferentes dos originais, o que certamente complexifica a transferência ou circulação de ideias. Entretanto Said identifica um determinado padrão neste movimento específico e sugere quatro estágios comuns para a viagem de qualquer teoria ou ideia. Em primeiro lugar há um ponto de origem, ou algo que se assemelhe a isso, um conjunto de circunstâncias que possibilitam o nascimento de uma ideia. Em segundo lugar, há uma distância transversalizada, isto é, uma passagem que atravessa a pressão de vários contextos conforme a ideia se move de um ponto prévio a outro espaço e época, onde assume uma nova proeminência. Terceiro, há um conjunto de condições de aceitação (e, como parte da aceitação, a resistência) que confrontam a ideia ou teoria transplantada, tornando possível sua introdução ou tolerância, não importando o quão alienígena esta possa parecer. Quarto, a ideia agora completa (ou parcial) e acomodada (ou incorporada) é em certa medida transformada pelos novos usos que fazem dela, sua nova posição em um novo espaço e tempo.

Para entender o trânsito internacional de ideias feministas, Cornelia Möser (2008) retoma os estágios de movimentação das ideias proposto por Said, adaptando- 
os às dimensões para a compreensão dos intercâmbios de ideias feministas através das fronteiras nacionais. A autora propõe, a partir dos estágios identificados por Said (1983), o estudo do trânsito de ideias feministas através dos processos de recepção, tradução, difusão e reapropriação. Möser analisa os debates sobre gênero entre França e Alemanha, sugerindo que ao invés de proceder a uma comparação clássica onde dois países são estudados separadamente, adote-se uma perspectiva interdisciplinar e transnacional revisitando as problemáticas feministas em termos de interação, transferências e viagens de ideias.

Para pensar a circulação de conhecimento feminista entre Brasil e França, apoiamo-nos também na abordagem de Appadurai (2008) sobre circulação global das formas, a qual se compõe de um nível abstrato de discussão sobre seus agentes: pessoas, commodities e ideias. Conforme Appadurai, o momento da globalização atual pode ser caracterizado como tendo alta conectividade nos novos níveis, formatos e tipos de circulação, observáveis tanto nos corpos e commodities, tanto quanto nas ideias, imagens e estilos. Há diversas formas de circulação presentes nas inúmeras paisagens da heterogeneidade da globalização que dependem dos circuitos, velocidades e alcance espacial. As condições para a circulação de conhecimento feminista podem portanto ser associadas da seguinte forma: pesquisadoras/militantes feministas (pessoas), publicando, traduzindo, organizando conferências (commodities), tratando de conhecimento feminista (ideias).

Tendo em vista o enfoque na dimensão da produção científica para a circulação do conhecimento feminista para este trabalho, fazemos uso da abordagem da obra de Cornelia Möser (2016) cujos marcos analíticos se fazem via retomada de ideias. Esta proposta analítica é apresentada em detrimento dos estudos comparativos baseados em similaridades ou diferenças, sendo considerada mais pertinente para o estudo da produção de pensamento feminista. Através desta proposta metodológica, procuraremos evidenciar fatores que permitem a expansão da circulação do conhecimento feminista, sem, no entanto, fazer uso de uma análise comparativa estrita dos periódicos selecionados.

A circulação da produção científica pode ser analisada através de análises de redes e conteúdos aplicadas a periódicos específicos sobre gênero e feminismo de 
ambos os países, os quais podem ser considerados mediadores culturais no tráfico de teorias e discursos feministas:

\begin{abstract}
Uma forma de se abordar a difícil tarefa de resolver a questão da importação/exportação de ideias feministas e as institucionalidades que supervisam este processo é desenvolver uma análise da circulação de conhecimentos (feministas) a partir de seus contextos de produção para seus contextos de recepção. [...] É bem sabido que os textos não viajam através de contextos linguísticos sem um 'visto'. Seu deslocamento pode acontecer somente se também houver um aparato material organizando sua tradução, publicação e circulação (COSTA; ALVAREZ, 2013, pp.580-581).
\end{abstract}

Assim, podemos analisar elementos que indiquem diálogos, trocas teóricas e parcerias internacionais de pesquisa a partir da identificação de temáticas publicadas, traduções de obras francesas e brasileiras, identificação colaborações estrangeiras nos periódicos franceses e brasileiros, tanto em termos de autorias, quanto em termos de comitê editorial.

\title{
III Percursos dos Feminismos entre Brasil e França
}

Inicialmente, podemos situar o interesse específico em analisar a contribuição resultante das trocas entre os feminismos brasileiro e francês, o qual não é fortuito. $\mathrm{Na}$ trajetória do feminismo mundial a contribuição do pensamento francês é central, suas raízes estão presentes na Revolução Francesa, com a publicação dos Direitos da Mulher e da Cidadã, publicado em 1791 por Olympe de Gouges, passando pela repercussão internacional de O Segundo Sexo de Simone de Beauvoir, em 1949, até chegar aos dias de hoje quando as universidades francesas e o próprio CNRS ${ }^{6}$ difundem o trabalho de pesquisadoras dedicadas ao desenvolvimento de pesquisas marcadamente feministas (ROUCH, 2001).

Há de se destacar igualmente a existência de uma ligação histórica iniciada nos anos 1970 de feministas brasileiras com o feminismo francês. Durante o período das ditaduras militares no Cone Sul, a França tornou-se um dos principais países a receber

\footnotetext{
${ }^{6}$ Centre National de la Recherche Scientifique (CNRS) é o Centro Nacional de Pesquisa Científica da França.
} 
exilados políticos sul-americanos, dentre os quais podemos destacar argentinos, chilenos e brasileiros (MARQUES, 2015; ABREU, 2010; FELITTI, 2008; COSTA, 1980). Dadas as circunstâncias, nos períodos sucessivos ao paradigmático ano de 1970 para o movimento feminista francês, havia uma concentração de mulheres latino-americanas em Paris. Estas acessavam diálogos com um feminismo que assumia um status transnacional após a sua segunda onda, o qual visava a transformação de práticas sociais de atores não-estatais, a ampliação da cidadania da mulher e a transposição das fronteiras geográficas a fim de disseminar valores e ideias:

\begin{abstract}
A força e a amplitude do movimento feminista francês foram extraordinárias, o que ficou demonstrado com a legalização do aborto em 1975 e a sua influência sobre mulheres de outros países que se encontravam na França. Dessa forma, o caráter transnacional do movimento feminista francês se torna evidente. Ao oferecer solidariedade às latino-americanas refugiadas na França, o movimento possuía objetivos mais amplos, assim como outras organizações e movimentos solidários que passaram a emergir nesse momento. Interessava às feministas francesas alcançar militantes de outros países para assim, possibilitar uma transformação social com proporções mundiais (MARQUES, 2015, p.126).
\end{abstract}

Durante o período de exílio político na França, muitas brasileiras puderam participar de grupos de discussão feminista e impulsionaram a formação de novas articulações, a exemplo da criação do Grupo Latino-Americano de Mulheres em Paris, em 1972, da criação da revista Nosotras em 1974, e do Círculo de Mulheres Brasileiras em Paris, uma organização política que atuou junto ao feminismo francês (ABREU, 2010, 2013; CARDOSO, 2014; PEDRO, WOLF, 2007). De acordo com Lucila Scavone (2011) o Círculo de Mulheres Brasileiras em Paris é um exemplo do contato estreito com o feminismo francês, ele abrigou brasileiras ligadas a partidos políticos e feministas autônomas que, ao regressarem ao Brasil, no começo dos anos 80 , continuaram, em sua maioria, vinculadas ao movimento e/ou à produção acadêmica.

A criação do Círculo de Mulheres Brasileiras ocorreu em 1976 como consequência de uma série de divergências ideológicas surgidas no interior do Grupo Latino Americano de Mulheres e do boletim Nosotras, do grupo feminista Comitê, de matriz chilena, mas também em resposta a crescente demanda do fortalecimento de grupos de estudos feministas (ABREU, 2010, 2013). Sendo composto por mulheres 
brasileiras vivendo na França sensibilizadas pelo movimento feminista internacional, o grupo tinha como objetivo debater, aprofundar e tomar uma real consciência da opressão específica que sofre a mulher nessa sociedade.

O Círculo ganhava legitimidade face à comunidade exilada, torna-se conhecido pelo movimento feminista francês e se transformava numa das mais bem estruturadas organizações de brasileiros no exílio e no mais importante grupo feminista de exiladas desta nacionalidade, chegando a congregar em suas assembleias mais de oitenta mulheres (ABREU, 2010). Introduziu na comunidade exilada uma questão relegada, impôs-se como grupo autônomo das organizações políticas e abriu um novo horizonte para muitas militantes de esquerda.

Albertina Costa (1980), em Memórias das mulheres do exílio, organiza uma série de depoimentos de mulheres brasileiras exiladas em diversos países em consequência da perseguição política do Estado Brasileiro a partir de 1964. Em um primeiro momento, muitas mulheres exilaram-se no Chile, onde foi criado "Comitê de mulheres brasileiras no exterior" também chamado "Comitê de mulheres brasileiras no Chile", organizado por Zuleika Alambert. O grupo no Chile durou pouco tempo devido ao golpe militar no país e centenas de exilados partiram para a França após 1973, incluindo-se a organizadora cuja militância política passou para uma ótica de fato feminista na Europa. Nos debates do grupo do Chile a militância era totalmente vinculada às ações e concepções das organizações armadas e pouco espaço havia para tratar da questão feminina (COSTA, 1980).

Especial importância é atribuída à Europa, em particular à França, na tomada de consciência sobre questões tais como a condição feminina na sociedade, o aborto e os métodos contraceptivos. Conforme os depoimentos publicados, a França nem sempre aparece como a primeira alternativa de destino, tendo em vista o idioma e a distância do Brasil, mas a concessão do status refugiados políticos às famílias brasileiras bem como a maior facilidade em obter trabalho e atendimento de saúde no país aparecem como fatores definitivos na escolha deste destino em comparação à Portugal, por exemplo. Este país, apesar de ter o idioma como facilitador, concedia apenas vistos de turismo, o que trazia dificuldades ao acesso de serviços públicos (COSTA, op. cit). 
A relação entre o feminismo francês e o brasileiro, iniciada nos anos 1970 destaca-se em comparação a relações com o movimento feminista de outros países que acolheram exiladas políticas (COSTA, Op.Cit; ABREU, 2010; MARQUES, 2015). Há uma particularidade envolvendo facilidades burocráticas no processo de exílio político bem como na aproximação ideológica feminista. A maior visibilidade do movimento feminista brasileiro coincidiu com o retorno de exiladas políticas ao país e a luta pela redemocratização (ALVAREZ, 1990). Muitas mulheres que retornavam da Europa ao Brasil, entre as décadas de 1970 e 1980, haviam entrado em contato com as ideias de maio de 68 e foram apresentadas aos movimentos e debates de feministas europeias e norte-americanas da época. Em especial, o surgimento do Mouvement Libération des Femmes (MLF), em 1970, e a explosão de novos grupos feministas nos Estados Unidos no contexto de reflexões teóricas pós-68 influenciaram a ampliação das pautas de discussão dos movimentos feministas, tais como a contraposição entre luta de classes e de sexos, a denúncia da violência contra as mulheres, a revalorização da sexualidade feminina, entre outras (FERREIRA, 2012; SCAVONE, 2011; ABREU, 2010; GROSSI, 2004).

A obra de Simone de Beauvoir é frequentemente citada entre as exiladas entrevistadas para a coletânea de memórias Memória de mulheres no exílio (1980). Beauvoir, além de ter sido uma das intelectuais precursoras do movimento feminista, foi uma das personalidades francesas solidárias às lutas dos exilados brasileiros na França (MARQUES, 2015). A aproximação de Beauvoir e do movimento feminista francês contribuiu para um posicionamento político e militante particular às mulheres brasileiras vivendo em Paris.

\section{III. a. Percursos dos estudos feministas no Brasil}

Em 1967, Heleieth Saffioti inaugurava os estudos sobre condição feminina no Brasil, através da defesa de sua tese de livre docência $A$ mulher na sociedade de classe: mito e realidade, sob orientação de Florestan Fernandes, na Faculdade de Filosofia, Ciências e Letras de Araraquara, da Universidade Estadual de São 
Paulo (UNESP). Sua tese foi publicada pela editora Vozes em 1976, tornando-se um marco para os estudos feministas brasileiros. A discussão acadêmica sobre a condição das mulheres iniciava-se, portanto, em meio a um contexto nacional de repressão política, mas também de resistências de diversos tipos.

No final dos anos setenta, a euforia participativa da militância de esquerda fazia-se visível também na universidade. O corpo docente de então, predominantemente jovem e de esquerda, era composto por professoras e professores cujas trajetórias pessoais envolviam a participação política em partidos então ilegais ou em movimentos estudantis na década anterior, com passagem pela prisão ou o retorno recente de estadias forçadas no exterior. O contexto era assim favorável à discussão dos movimentos sociais que estavam presentes na sociedade mais abrangente e à discussão de ideias democráticas dentro das salas de aula (CORRÊA, 2001).

Devido à ditadura militar, o feminismo se desenvolve com algumas particularidades, assume um caráter marcado pela luta de classe e contra a ditadura que marca as primeiras publicações feministas dos anos 70 vide os Jornais Brasil Mulher e Nós, Mulheres, (GROSSI, 2004; COSTA, SARDENBERG, 2014). A essa característica, juntava-se a preocupação com a pesquisa das integrantes do movimento feminista, em sua maioria intelectualizadas e oriundas de camadas sociais médias.

Em 1979, um passo importante no incentivo à produção científica nesta área será dado com a criação do Grupo de Trabalho (GT) Mulher e Força de Trabalho na Associação Nacional de Pós-Graduação e Pesquisa em Ciências Sociais (ANPOCS) ${ }^{7}$ e, posteriormente, em 1980, na mesma Associação, com a criação do GT Mulher e Política (Costa e Sardenberg, 2014; Grossi, 2004). Nos anos 1990, duas das mais importantes revistas acadêmicas sobre gênero e feminismos são lançadas. Em 1992 é publicada a Revista de Estudos Feministas, com apoio da Fundação Ford, e em 1993 é a vez da primeira publicação da Cadernos Pagu, que conta com o apoio da

\footnotetext{
${ }^{7}$ Criada no Brasil em 1977.
} 
Fundação de Amparo à Pesquisa do Estado de São Paulo (FAPESP) e do Conselho Nacional de Desenvolvimento Científico e Tecnológico (CNPq).

Com a disseminação da categoria de análise de gênero, a partir de 1990, houve um impulso no processo de criação dos núcleos, sendo que a partir desta década, estes incorporaram a definição de Gênero em seus nomes, em contraposição aos Núcleos de estudo sobre a mulher da década anterior.

Alguns anos atrás, Margareth Rago (1998) sublinhou a necessidade de aprofundar um debate brasileiro sobre a pertinência de uma teoria do conhecimento feminista. Visando contribuir para esta discussão, a autora afirmou:

\begin{abstract}
Afinal, se considerarmos que a epistemologia define um campo e uma forma de produção do conhecimento, o campo conceitual a partir do qual operamos ao produzir o conhecimento científico, a maneira pela qual estabelecemos a relação sujeito-objeto do conhecimento e a própria representação de conhecimento como verdade com que operamos, deveríamos prestar atenção ao movimento de constituição de uma (ou seriam várias?) epistemologia feminista, ou de um projeto feminista de ciência. O feminismo não apenas tem produzido uma crítica contundente ao modo dominante de produção do conhecimento científico, como também propõe um modo alternativo de operação e articulação nesta esfera (RAGO, 1998, p.26).
\end{abstract}

Embora a atual conjuntura política nacional evidencie uma complexidade que exige discussões teóricas aprofundadas e conectadas, os estudos de ciências sociais no Brasil pautam-se por modelos de análises limitantes. Esta crítica é feita por Flavia Biroli (2012), para quem a ciência política produzida no país carece de "pegada teórica":

No Brasil, a penetração da teoria política feminista ainda é incipiente. A maior parte da ciência política, aqui como em outros países, se prende a modelos simplistas, que estilizam por completo as motivações dos agentes políticos e se limitam a um conjunto bastante restrito de questões, sobretudo os processos eleitorais, o comportamento legislativo e as relações entre os poderes. É uma ciência política sem pegada teórica, fortemente vinculada ao senso comum, portanto incapaz de aderir à agenda de pesquisa que a teoria feminista abre. (BIROLI, 2012, p.10).

O campo de pesquisa feminista brasileiro tem cerca de 50 anos diferenciandose, portanto, de outras tradições intelectuais do ocidente onde os estudos sobre mulheres remontam ao período entre guerras do século XX. Em um contexto de repressão política, ele surge com a peculiaridade de trazer consigo o caráter de luta 
por espaços democráticos, na sociedade e na academia. De estudos sobre a condição feminina, surgem grupos de estudo que por sua vez ocupam espaços nas associações universitárias de ciências humanas, surgem núcleos de pesquisa e revistas acadêmicas os quais contam com o apoio inicial de fundações estrangeiras para pesquisa. Em duas décadas, de 1970 a 1990, de trabalho pesquisa e trocas internacionais, pôde se firmar um campo de estudos feministas e de gênero. Este percurso é permeado de desafios que surgem a nível individual, conforme as trajetórias de pesquisadoras feministas relatam, chegando ao nível institucional. Em todos esses níveis, os desafios abarcam a constante necessidade de rebater argumentos que deslegitimam a validade de tais estudos.

\section{III.b.Percursos dos estudos feministas na França}

A Europa pós Maio de 68 propiciou a eclosão de uma nova fase do Feminismo a qual impulsionou os estudos e pesquisas sobre "as mulheres". Munido de uma crítica radical ao patriarcado, o feminismo deste momento histórico preocupava-se em denunciar a opressão das mulheres no espaço público e no espaço privado, partindo de um olhar político libertário, o qual visava à autonomia política, tratando das relações entre os sexos sob um prisma até então inexplorado.

Um dos marcos desta nova onda feminista na França foi a publicação, em julho de 1970, do número especial da revista Partisans "Libération des Femmes/Année Zero", que contou com uma apresentação do Movimento de Liberação das Mulheres (Mouvement de Libération des Femmes - MLF) e evidenciava a emergência de novas ideias do pensamento feminista e de uma nova esquerda, bem como as principais preocupações teóricas e políticas do movimento francês "luta de classes ou de sexos"; "o trabalho invisível"; "o mito da frigidez e do orgasmo feminino"; "política sobre o aborto"; "economia política da liberação das mulheres", "o estupro"; "a maternidade", entre outros. Na França os estudos sobre as mulheres foram um aporte do MLF, movimento responsável pelo ao apoio à inserção estudos sobre as mulheres na universidade e perturbador da ordem científica estabelecida, por constituir-se 
simultaneamente enquanto crítica epistemológica, política e institucional à ciência que excluía os estudos sobre as mulheres do escopo de objetos científicos legítimos (LAGRAVE, 1990).

Tomando-se como marco o feminismo materialista francês desenvolvido a partir das reflexões do MLF durante os anos 1970, podemos apresentar de forma breve a evolução cronológica do pensamento feminista na França. A discussão em torno da substituição do conceito feminismo pelo conceito gênero, durante os anos 1980; a discussão sobre paridade política e igualdade de participação assim como a denúncia da invisibilização do pensamento feminista francês através da criação americana da French Feminism nos anos 1990, pós-colonialismos e interseccionalidades a partir dos anos 2000. Vale ressaltar que as temáticas da agenda de pesquisa feminista francesa aqui selecionadas e sintetizadas cronologicamente não necessariamente esgotam-se a partir da emergência de uma temática sucessória. Estas podem se interseccionar, se reciclar e serem reutilizadas de acordo com os contextos sócio-políticos analisados pela pesquisa social.

Conforme apontado por Eleni Varikas (2012), a partir dos anos 1990, a diversidade racial e social expande-se no ambiente universitário francês, o que impactou no aprendizado e na maneira de se fazer pesquisa. A partir da metade dos anos 1990 as questões sobre a constituição da alteridade, a subjetividade, a resistência, haviam tomado o lugar das discussões sobre as classes sociais. Começava-se a tratar da homofobia, evocando-se a questão da sexualidade como uma experiência de exclusão.

Assim como as experiências de exclusão começam a ser associadas à sexualidade, assistimos a partir dos anos 2000 , a um movimento de inserir sujeitos até então pouco discutidos nos círculos acadêmicos franceses. A problematização do feminismo em sociedades multiculturais e a consideração do contexto pós-colonial, evidenciam e intensificam a discussão de temas tais como o feminismo islâmico (ALI, 2012), as mulheres e o véu islâmico, as mulheres imigrantes e as mulheres da periferia. As análises, em compasso com a lógica das interseccionalidades, buscam suporte em teorias cuja origem de uso está na no Sul Global, como é o caso das referências à obra de Quijano (2005), e a teóricas do feminismo negro ou latino- 
americano a fim de compreender a realidade social que as teorias do pensamento político e sociológico europeu têm dificuldade em explicar.

\section{Mapeamento da circulação do conhecimento feminista entre Brasil e França}

A discussão da circulação internacional de ideias feministas nos eixos propostos envolve pensar no espaço conferido às produções do Sul, bem como as relações de poder no campo acadêmico internacional feminista, relações de dominação e opressão no que Marlise Matos (2012) entende se assentar a geopolítica do conhecimento. Ao discutirmos o conhecimento feminista, devemos estar atentas, portanto, a que este é sempre situado epistemicamente, entre os dois pólos das relações de poder, a saber, o lado dominante ou o lado subalterno. Tal abordagem resulta do diálogo com uma perspectiva epistêmica descolonial, cuja proposta envolve perspectivas do Sul Global a partir de corpos e lugares étnico raciais/sexuais subalternizados e um mundo pluriversal ao invés de universal. Mohanty (1988) e Cusicanqui (2010) destacam a importância das alianças teóricas do Sul indicando também a necessidade de uma epistemologia autônoma e crítica às colonialidades hegemônicas na discussão da circulação de ideias feministas.

Ainda em tempo, Claudia Lima Costa e Sonia Alvarez (2013) destacam que as viagens e traduções das teorias feministas são feitas a partir das mediações exercidas pelas revistas e periódicos científicos. Ao tratarmos da circulação internacional de ideias, parece válido considerar o papel do mercado de citação transnacional na construção do cânone feminista, o qual, invariavelmente, carrega consigo um caráter anglófilo e excludente de outros idiomas. $O$ inglês, adquiriu um status global que impacta não somente no meio linguístico de publicações, mas também determina os trabalhos que são citáveis, sendo determinante sobre qual conhecimento (ou conhecimento de quem) pode circular. Desse modo, há de se considerar que a língua inglesa não deve ser vista como um meio transparente que apenas "traduz". Seu status dentro dos sistemas de avaliação dá forma ao que se considera ser o conhecimento, privilegiando publicações e citações em inglês. 
Tendo desenvolvido os marcos teóricos, epistemológicos e metodológicos para a análise da circulação do conhecimento feminista, realizamos aqui a análise dos meios pelos quais o conhecimento feminista viaja ou circula no eixo Brasil-França. Assim, para verificar as condições que produziram os dois momentos de convergência intensificada, apoiamo-nos na metodologia qualitativa para análise de conteúdo de periódicos acadêmicos brasileiros e franceses.

Selecionamos três periódicos que tratam de gênero e feminismos para os dois países analisados, contemplando o período que parte de seus números de lançamentos até as publicações de 2016. Definimos como material de análise para a produção científica no Brasil a Revista de Estudos Feministas (REF), Cadernos Pagu e Labrys. Para a análise da produção científica na França, selecionamos os periódicos feministas Quéstions Féministes/Nouvelles Quéstions Féministes (NQF), Cahiers du CEDREF e Cahiers du Genre, procurando establecer para a análise uma periodicidade paralela a seus pares brasileiros. Nestes periódicos específicos sobre gênero e feminismo, procuramos identificar a abertura para autorias e temáticas internacionais nos números e também identificar qual o espaço das revistas francesas conferido às autorias brasileiras e vice-versa.

\section{IV. a. Periódicos brasileiros}

Tanto a REF, quanto PAGU e Labrys dividem o Portal de Publicações Feministas e mais recentemente o Portal do IEG, relacionado a publicações de ONGs feministas e a revistas estrangeiras, em quese compartilham momentos reflexivos de troca de experiências sobre publicações feministas e de gênero. O esforço em construir um canal de expressão do movimento de mulheres e a tradução de artigos em inglês para o português integravam o mote das recém-lançadas revistas REF e PAGU, no início dos anos 1990, em um contexto de veloz proliferação de núcleos de pesquisa na área. Ambas as revistas se firmaram como referências de excelência entre os periódicos de Ciências Humanas do Brasil, disponibilizando suas versões eletrônicas na SciELO Social Sciences (SSS) a partir de meados dos anos 2000. 
Durante a primeira década da REF (1992-2002) a colaboração internacional era mais intensificada com os Estados Unidos e a França, do que com a América Latina, vide as traduções de artigos em francês e inglês, bem como a publicação de entrevistas com feministas francesas e americanas. A inserção das autoras hispanoamericanas na revista em sua primeira década, o que indicava o distanciamento de diálogo com as vizinhas latino-americanas, a despeito da proximidade geográfica e linguística.

Em sua segunda década de publicações (2003-2013), a REF buscou aproximar seu público leitor dos debates internacionais através da realização de entrevistas com pensadoras-referência do feminismo. A revista demonstrou preocupação em traduzir para o português a contribuição de teóricas de várias nacionalidades e promover o diálogo entre as estudiosas brasileiras e demais nacionalidades, atualizando sua inserção nos fluxos globais do pensamento feminista.

A Cadernos Pagu esteve vinculada desde sua criação em 1993 a um núcleo universitário como forma de viabilização, já que não contava com recursos externos. Este constitui uma das principais diferenças da proposta inicial da REF, a qual defendia a não institucionalização da publicação, contando com o apoio inicial da Fundação Ford. As colaborações internacionais francesas e estadunidenses, apesar de pouco representativas na revista, ganham destaque em detrimento da baixa colaboração de latino-americanas, em um quadro muito semelhante ao da primeira década REF.

Em 1999, os Cadernos Pagu chamam atenção pelo Dossiê especial dedicado aos 50 anos da obra prima de Simone de Beauvoir. Este dossiê contou com o apoio de Beth Lobo, Heleieth Saffioti e Michelle Perrot deixando transparecer a rede colaborativa de pesquisa feminista que se firmou ao longo dos anos 1990 em diante.

Ao considerarmos a continuidade das publicações da Cadernos Pagu até o ano de 2016, percebemos a consolidação desta rede de colaboração feminista. Há traduções de artigos franceses sobre gênero ou feminismo para o português, artigos tratando do contexto francês e da relação França-Brasil há época da ditadura militar no cone sul, e as citações a obras do feminismo francês são recorrentes. É notável o interesse de editoras da revista em estimular uma leitura crítica da produção 
internacional. Estas aludem à relação na produção de conhecimento estabelecida por Gayatri Spivak, autora indiana que propõe confrontar teorias de elite do Primeiro Mundo com as questões coloniais para abri-las, questioná-las, implodi-las.

A Labrys, études féministes/estudos feministas é por sua vez, uma revista online internacional lançada em 2002, multilíngue, e indexada pela Capes e pela Biblioteca Nacional da França. Organizada por Tania Navarro, a revista apresenta temáticas do feminismo francês, abordando o feminismo radical e sua articulação com a obra de Foucault, a mulher lésbica - questão de fundo para MLF nos anos 1970 bem como referências à obra de Monique Wittig.

A despeito de um forte vínculo com autorias e temáticas do feminismo francês, nas últimas edições da Labrys (entre 2010 e 2016) é expressada uma preocupação em expandir as vozes feministas do Sul Global. Os dossiês sobre o feminismo na Índia, bem como as seções que tratam da história do feminismo e da pesquisa feminista a partir de um olhar das margens, dissidências epistemológicas, com discussões sobre o contexto pós-coloniais de países da América Latina, da África, Ásia, Oriente Médio e Oceania atestam tal preocupação. Por meio da diversidade textual, temática, linguística e geográfica, a revista denota estar atenta aos fluxos globais do pensamento feminista, buscando dar espaço ao crescente espectro teórico feminista e garantindo a promoção de diálogos entre feminismos dissidentes e do Sul Global.

\section{IV. b. Periódicos franceses}

No que tange os periódicos franceses, ganha destaque a publicação de Andrée Michel sobre as lutas feministas no Brasil "Luttes féministes au Brésil: notes sur un récent Voyage: avril-mai 1989", publicado no Número 16/17/18 da Nouvelles Questions Féministes (NQF) em 1991. A publicação fazia referência à passagem de Andrée pelo Brasil em 1989, onde observou os rumos do movimento feminista durante a transição democrática.

Observamos o dossiê especial de 2005, sobre Feminismos Dissidentes na América Latina e Caribe, com artigos de autoras da região, tratando das lutas de 
resistência à globalização, e de alternativas ao capitalismo global, do movimento zapatista no México, do Movimento dos Sem-Terra (MST) no Brasil, das Piqueteras na Argentina e das lutas pela nacionalizaçãodos hidrocarburetos na Bolívia. Nessa edição, dois textos de autorias brasileiras foram traduzidos por Jules Falquet à NQF: "Noircir le féminisme", de Sueli Carneiro, e "lalodês et féministes. Réflexions sur l'action politique des femmes noires en Amérique latine et aux Caraïbes", de Jurema Werneck. Ademais, esta edição da revista contou com uma versão em língua espanhola de diversos artigos, incluindo a publicação de um artigo de Ochy Curiel, importante pensadora do feminismo latino-americano.

Mais recentemente, observamos a intensificação das interfaces teóricas dos feminismos francês e latino-americano. A Revista acadêmica NQF em seu editorial expressa interesse em explorar e difundir feminismos dissidentes, a exemplo dos debates sobre as mulheres indígenas e negras da América Latina, e das lutas das mulheres negras no Brasil, das discussões que unem racismo à opressão das mulheres, e à heterossexualidade como sistema. Essas temáticas, no início dos anos 2000, encontravam pouco espaço para discussão acadêmica inclusive no próprio país de origem.

Já nos números da revista Cahiers du Cedref, cujas perspectivas partem das pós-colonialidades de gênero, teorias feministas e teorias queers decoloniais, interseccionalidade e colonialidade, são também verificadas interfaces teóricas com o feminismo latino-americano. Há publicações de autorias mexicanas, tais como Gloria Anzaldua, precursora da ideia de consciência mestiça no pensamento feminista, e de outras cinco brasileiras: Lélia González, Claudia Pons Cardoso, Anette Goldberg Salinas, Céli Regina Jardim Pinto e Albertina de Oliveira. Com a tradução de seu texto "A categoria político-cultural da amefricanidade", Lélia Gonzalez integra a lista de autoras da última edição da revista, n.20, 2015, acompanhada de Cláudia Pons Cardoso, em um artigo homenagem à González, precursora do feminismo negro no Brasil. Anette Goldberg, muito associada às mulheres brasileiras vivendo em Paris nos anos 70, publica no n.8-9, em 2000, um artigo sobre as brasileiras exiladas, fazendo também a apresentação do Dossiê Mulheres e Migração. Em 1997, na edição de n.6 do CEDREF, há a publicação de Albertina Oliveira tratando sobre os estudos 
sobre a mulher no Brasil, e de Celi Pinto, tratando sobre a dupla característica feminista: movimento social e sujeito político.

É notável o esforço editorial da revista em trazer temáticas que ultrapassem o escopo meramente europeu de reprodução de desigualdades de gênero e sexo, bem como autorias internacionais, não apenas brasileiras, mas também de outros continentes do globo. Nesse sentido, vale observar a composição do comitê editorial da revista. Contando com uma relativa diversidade geográfica de suas 16 membras, o comitê é composto pela brasileira Miriam Grossi, bem como pela francesa Jules Falquet, pesquisadoras que transitam frequentemente no eixo de circulação do conhecimento feminista Brasil-França.

Por fim, a Revista Cahiers du Genre, lançada em 1991, conta uma série de publicações tratando de análises sobre o contexto brasileiro cujas autorias são também brasileiras. Merece destaque o dossiê n.4 de 1992, cuja abordagem aproxima análises de gênero sobre o contexto francês e brasileiro "estratégias familiares e de emprego: perspectiva franco-brasileira". Neste dossiê, bem como nos demais da primeira década da revista, há uma série publicações cujas autorias são brasileiras. As temáticas incluem relações de trabalho e gênero, paternidade, envelhecimento, políticas públicas para mulheres, violências e direitos reprodutivos. A revista, ao trazer análises sobre o contexto do Brasil ou da América Latina, evidencia uma predominância nos recortes da sociologia do trabalho e da abordagem das relações sociais de sexo. No entanto, apresenta abordagens feministas plurais, contando com a participação em seus comitês editoriais de nomes tais como Eleni Varikas, Jules Falquet e Genevieve Fraisse. A constante aparição do apoio para a difusão internacional de tais autoras sediadas na França indica o esforço por parte de pesquisadoras francesas em tecer uma rede colaborativa internacional com o Brasil.

Os dados aqui abordados reiteram parcialmente as hipóteses sobre a circulação do pensamento feminista entre Brasil e França. Em um primeiro plano, percebemos que, em termos de conteúdo, há um esforço de tradução e entrevistas com teóricas feministas francesas nos periódicos feministas brasileiros. Há o reconhecimento das dificuldades em transpor a barreira da geografia do conhecimento e também do desafio de integrar as temáticas de gênero e feminismo a pautas mais 
amplas do pensamento político social, tais como a democracia, a justiça e as instituições políticas. Dentre as colaborações teóricas internacionais nas revistas específicas sobre gênero e feminismo, destacam-se aquelas de origem francesa tanto no formato de artigo quanto no de entrevista. Por outro lado, o recente aumento da participação de colaborações latino-americanas para as revistas pode indicar uma maior abertura não apenas brasileira como também internacional para a contribuição do pensamento feminista latino-americano.

Os periódicos de ambas as regiões analisadas apresentam uma orientação de publicação consciente das relações entre teorias metropolitana/centrais e traduções periféricas, bem como do silenciamento de outras genealogias feministas, especialmente nas práticas de tradução de artigos em língua estrangeira. $O$ questionamento do que é considerado conhecimento, a superação de fronteiras geopolíticas do conhecimento, tráfico de teorias e a abertura de espaço às produções teóricas do Sul Global são pontos que transparecem ao longo das análises aqui realizadas. Além disso, a análise da composição do corpo editorial dos periódicos selecionados e sua representação no contexto discursivo mais amplo suscitam conjeturas sobre o desenvolvimento das redes científicas de colaboração. Há uma série de pesquisadoras com grande participação no circuito de revistas feministas, congressos, parcerias institucionais. Eleni Varikas, Jules Falquet. Françoise Picq, Genevieve Fraisse, Helena Hirata, Lena Levinas, Beth Lobo, Miriam Grossi, pesquisadoras com participação em seus diversos editoriais, sediadas na França ou no Brasil, exercem um papel fundamental na diversificação de abordagens feministas em periódicos, e promovem a divulgação de feminismos estrangeiros. Esse papel destaca a capacidade de tais pesquisadoras em promover a difusão internacional de trabalhos feministas para seu público nacional e indica o esforço por parte destas em tecer uma rede colaborativa internacional no eixo Brasil-França.

\section{Considerações finais}

Buscamos ao longo deste artigo reunir abordagens históricas, teóricas e epistemológicas que nos indicassem percursos investigativos para o desenvolvimento 
de um mapeamento das viagens do conhecimento feminista entre os campos de pesquisa brasileiro e francês. O exercício proposto pelas travelling theories de pensar os processos de recepção, tradução, difusão e reapropriação de ideias combinado à abordagem da circulação das formas, levam-nos a pensar no modo de produção do conhecimento feminista em consonância com as críticas à geopolítica do conhecimento.

A literatura que trata do pensamento feminista confirma o fluxo de ideias feministas vindas da França em direção ao Brasil entre os anos 1970 e 1985 . Da mesma forma, entre os anos 2000 e 2016, constatamos a expansão e dinamização globais dos fluxos teóricos feministas, posicionamentos epistemológicos críticos à hegemonia eurocêntrica são disseminados, e as ideias feministas oriundas do Sul Global ocupam maior espaço nas discussões acadêmicas na lógica da circulação de ideias. A partir da análise de conteúdo da produção científica de três periódicos franceses sobre gênero e feminismo, identificamos uma abertura do país à produção científica brasileira, por meio da publicação de obras relacionadas à temáticas do feminismo latino-americano, negro, pós-colonial e decolonial. Ao analisarmos os equivalentes brasileiros, percebemos uma abertura histórica à produção intelectual francesa, que no entanto se altera em função da maior receptividade às produções dos Estados Unidos e do Sul Global.

As análises aproximam-se da descolonização dos saberes, para questionar a transferência de conhecimentos, a circulação de idéias, e perguntar o que aprendíamos até então, o que aprendemos hoje, o que podemos aprender com os outros, quem quer que seja ou da onde quer que venha. Percebe-se portanto uma reconfiguração global do campo de conhecimento feminista, onde as viagens teóricas de uma região a outra intensificam-se e, se diversificam.

Ademais, percebe-se a preocupação de tais periódicos em tornar sua produção científica alinhada a ideia de feminismos globais que contemple o Sul e ao posicionamento crítico à hegemonia científica eurocentrada. Esta preocupação é expressada tanto na apresentação dos periódicos analisados, quanto na composição dos corpos editoriais, os quais são compostos por uma diversidade de nacionalidades e onde pesquisadoras brasileiras se fazem presentes. 
Neste trabalho, pudemos explorar um dos fatores que compõem o quadro de circulação internacional de conhecimento, qual seja, os fluxos de produção científica existentes entre ambos os países. Desse modo, a proposta deste trabalho constituiu um primeiro passo para o entendimento da circulação de ideias na agenda de pesquisa feminista brasileira e a compreensão dos rumos dinâmicos e transfronteiriços dos debates feministas presentes na comunidade científica da atualidade. Para darmos continuidade a essa reflexão será incorporada uma segunda etapa metodológica: incluiremos a análise de entrevistas semi-estruturadas aplicadas a pesquisadoras francesas e brasileiras cujas trajetórias intelectuais e políticas perpassem os diálogos entre o pensamento feminista francês e brasileiro, tanto historicamente quanto nos dias de hoje.

Os elementos aqui discutidos indicam uma continuidade no processo de intercâmbios teóricos feministas entre Brasil e França, embora sua dinâmica seja variável, e diretamente relacionada à expansão das redes através das triangulações feitas pelos Estados Unidos e pelos vizinhos latino- americanos, tais como Argentina e México. O mapeamento da circulação do conhecimento feminista no eixo proposto que congregue as etapas adicionais de análise permitirá identificar condições sóciopolíticas para o desenvolvimento no campo internacional de pesquisa feminista.

Pesquisas futuras poderão ampliar o escopo analítico da circulação de pensamento feminista, atentando às triangulações e buscando incorporar à produção intelectual demais grupos feministas latino-americanos surgidos na Europa, tais como grupos existentes em Portugal, Holanda e Suécia. O desenvolvimento do campo de estudos feministas na Argentina e Chile, países com históricos políticos de ditadura militar e exílio, poderão ser incluídos nas análises de modo a elucidar os atuais desafios de ampliação da colaboração feminista no Cone Sul. A expansão do escopo analítico, incluindo países latino-americanos, países europeus e também os Estados Unidos, permitirá desenvolver um mapeamento que revelará as reverberações feministas dos desafios à circulação global de conhecimento e de epistemologias dissidentes que pensam os feminismos do Sul Global.

\section{Referências Bibliográficas}


ABREU, Maira Luiza. Nosotras: feminismo latino-americano em Paris. Estudos Feministas. v. 21, n. 2, p.553-572, 2013.

- Feminismo no exílio: o Círculo de Mulheres Brasileiras em Paris e o Grupo Latino-Americano de Mulheres em Paris / Dissertação demestrado em Sociologia pela Universidade Estadual de Campinas, 2010.

ABREU, Maira Luiza; CARVALHO, Adília. Sisterhood is powerful: exílio e mobilizações feministas na França em apoio às "Três Marias". Lutas Sociais, v. 18, n. 32, p. 133147, 2014.

ADKINS, Lisa; LEONARD, Diana. Reconstructing French Feminism: Commodification, Materialism and Sex.London: Taylor \& Francis, 2005.

ALCOFF, Linda e POTTER, Elizabeth. Feminist Epistemologies. Routledge, New York, 1993.

ALI, Zahra. Féminismes Islamiques. Paris: la Fabrique, 2012.

ALMEIDA, Sandra Regina Goulart. Intervenções feministas: pós-colonialismo, poder e subalternidade. Estudos Feministas,v.21, n.2, p.689-700,,2013.

ALVAREZ, Sonia. Para além da sociedade civil: reflexões sobre o campo feminista. Cadernos Pagu n.43, p.13-56, 2014.

Engendering democracy in Brasil: women's moviments in transition politics. Pinceton: Princeton University Press. 1990.

APPADURAI, Arjun. The circulation of forms. Excerpt of a keynote lecture delivered on September 28, 2007, at a Conference on "Loose Canons", New York University, Department of Media, Culture and Communication, 2007.

BHABHA, Homi. Les lieux de la culture. Une théorie postcoloniale. Paris: Payot, 2007.

BIROLI, Flávia e MIGUEL, Luis Felipe. Teoria Política e feminismo, abordagens brasileiras. Vinhedo: Editora Belo Horizonte, 2012.

COSTA, Albertina de O., et al. Memórias de mulheres no exílio. Rio de Janeiro: Paz e Terra, 1980.

COSTA, Cláudia de Lima; ALVAREZ, Sonia E. A circulação das teorias feministas e os desafios da tradução. Estudos Feministas, 21(2): 336,2013.

COSTA, Cláudia Lima. As teorias feministas nas Américas e a política transnacional da tradução. Revista Estudos Feministas, v. 8, n. 2, p. 43-49, 2000.

DELPHY, Christine. L'ennemi principal: Tome 2, Penser le genre. Collection Nouvelles Questions féministes. Paris: Editions Syllepse, 2000. 
. The Invention of French Feminism: An Essential Move. Yale French Studies, n.. 87,. p. 190-221, 1995.

DORLIN, Elsa (dir.) Sexe, Race, Classe, pour une épistémologie de la domination. Actuel Marx Confrontation. Paris: Presse Universitaire de France, 2009.

FEMENIAS, María Luisa. Esbozo de un feminismo latinoamericano. Revista Estudos Feministas, v. 15, n. 1, p. 11-25, 2007.

FERREIRA; Rea. De um país ao outro: passagens entre a França e o Brasil. Entrevista com Miriam Pillar Grossi. Passages de Paris (APEB-Fr), v. 7, p. 4-22, 2012

FERREIRA, Verônica; ÁVILA, Maria Betânia; FALQUET, Jules; ABREU, Maira (org.). O Patriarcado Desvendado. Teorias de três feministas materialistas: Colette Guillaumein, Paola Tabet e Nicole-Claude Mathieu. Recife: SOS corpo, 2014.

FELITTI, Karina.Traduciendo prácticas, tejiendo redes, cruzando fronteras. Itinerarios del feminismo argentino de los '70s. Cadernos Pagu (44), p. 229-260, 2015.

FRASER, Nancy. From Redistribution to Recognition? Dilemmas of Justice in a 'PostSocialist' Age. New Left Review, 68-93, 1995.

GALSTER, Ingrid. Beauvoir dans tous ses états. Paris: CNRS éditions, 2007.

GOLDBERG, Anette. Brésiliennes en exil. Les cahiers du CEDREF [En ligne], 8$9 \mid 2000$, mis en ligne le 19 août 2009

. Féminisme contemporain au Brésil. Revue HSAL. N4, mai 1996.

. Os movimentos de libertação da mulher na França e na Itália (1970-1980): primeiros elementos para um estudo comparativo do novo feminismo na Europa e no Brasil. In: LUZ, Madel T. (org.). O lugar da mulher: estudos sobre a condição feminina na sociedade atual. Rio de Janeiro: Graal, 1982.

GOLDBERG, Anette e ZAIDMAN, Claude. Présentation du Réseau Femmes en migrations. Les cahiers du CEDREF [En ligne]2000.

GOUGES, Olympe de. Femme, réveille-toi! Déclaration des droits de la femme et de la citoyenne. Éditions Gallimard, 2014.

GONÇALVES, Eliana; PINTO, Joana Plaza. Reflexões e problemas da "transmissão" intergeracional no feminismo brasileiro. Cadernos Pagu (36), pp.25-46, janeiro-junho, 2011.

GROSSI, Miriam Pillar. A Revista Estudos Feministas faz 10 anos: uma breve história do feminismo no Brasil. Rev. Estud. Fem., Florianópolis, v. 12, n. spe, p. 211 221, Dec. 2004. 
GROSSI Miriam Pillar; RIAL, Carmen Sílvia Moraes. Nem Deus, nem amo, nem marido: uma trajetória do feminismo na Argentina - entrevista com María Luisa Femenías. Estudos Feministas.Vol.17 no.3 Florianópolis Sept./Dec.2009.

GROSSI, Miriam; MINELLA, Luzinete; PORTO, Rozeli. Depoimentos: trinta anos de pesquisas feministas brasileiras sobre violência. Florianópolis: Mulheres, 2006.

HARAWAY, Donna. Situated Knowledges: The Science Question in Feminism and the Privilege of Partial Perspective. Feminist Studies Vol. 14, No. pp. 575-599, 3, Autumn, 1988.

HARDING, Sandra. Is Science Multicultural? Postcolonialisms, Feminisms, and Epistemologies. Bloomington and Indianopolis: Indiana University Press, 1998.

A instabilidade das categorias analíticas na teoria feminista. Estudos feministas, n. 1, p. 7-31, 1993.

. Is There a Feminist Method? In: Feminism and Methodology, Bloomington and Indianopolis: Indiana University Press, 1987.

LAGRAVE, Rose Marie. Recherches féministes ou recherches sur les femmes? Actes de la recherche en sciences sociales. Vol. 83. Masculin/féminin-1. pp. 27-39, , juin 1990.

LUGONES, María. Colonialidad y gênero. Tabula Rasa, no 9, Universidad Colegio Mayor de Cundinamarca. Bogotá, Colômbia, pp 73-101, julio-deciembre, 2008. p. 3-19, 1987.

"Playfulness, 'World'-Travelling, and Loving Perception." Hypatia, v. 2, n. 2,

LUSTE BOULBINA, Seloua. "La décolonisation des savoirs et ses théories voyageuses», Rue Descartes (n 78), p.19-33, 2/2013

MARQUES, Teresa Cristina. A Esquerda brasileira exilada e o feminismo: a atuação política das brasileiras no Chile e na França (1968-1979). Projeto História, São Paulo, n. 52, p. 112-139, Jan.-Abr. 2015

MATOS, Marlise. A Quarta onda feminista e o Campo crítico-emancipatório das diferenças no Brasil: entre a destradicionalização social e o neoconservadorismo político. 38ํㅡㄹ Encontro Anual da ANPOCS, Caxambu, p.1-28, 2014.

.. Movimento e teoria feminista: é possível reconstruir a teoria feminista a partir do sul global? Revista de sociologia e política18 (36), jun. 2010, pp.67-92.

MENDES, Natália Pietra. Com a palavra: O Segundo Sexo. Percursos do pensamento intelectual feminista do Brasil nos anos 1960. Tese de doutorado, Porto Alegre: UFRGS, 2008. 
MIGUEL, Luis Felipe. Feminismo e política: uma introdução. Luís Felipe Miguel, Flávia Biroli. - 1ed. - São Paulo: Boitempo, 2014.

MOHANTY, Chandra. Under Western Eyes: Feminist Scholarship and Colonial Discourses. Feminist Review n.30, p.61-88, Autumn 1988.

MÖSER, Cornelia. Féminismes en traduction: théories voyageuses et traductions culturelles. Paris: Éditions des Archives contemporaines, 2013.

SAID, Edward W. The world, the text and the critics. Harvard University Press, 1983.

OLESEN, Virginia L. Os feminismos e a pesquisa qualitativa nesse novo milênio. In: DENZIN, Norman; LINCOLN, Yvonna. O Planejamento da pesquisa qualitativa. Teorias e abordagens. Org. Porto Alegre: Artmed, 2010. p. 219 - 258,

PINTO, Céli. Feminismo, História e Poder. Sociologia e Política, v. 18, n. 36, p. 15-23, 2010.

QUIJANO, Aníbal. A colonialidade do saber: eurocentrismo e ciências sociais. Perspectivas latino-americanas. Buenos Aires: CLACSO, 2005.

RAGO, Margareth. Epistemologia feminista, gênero e história. In: PEDRO, Joana; GROSSI, Miriam. Orgs. Masculino, feminino, plural. Florianópolis: Ed. Mulheres, 1998.

Os feminismos no Brasil: dos "anos de chumbo" à era global. labrys, estudos feministas, número 3, janeiro/ julho 2003.

RIVERA CUSICANQUI, Silvia. Ch'ixinakax utxiwa: una reflexión sobre prácticas y discursos descolonizadores. 1a ed. - Buenos Aires: Tinta Limón, 2010.

ROUCH, Hélène. Recherches sur les femmes et recherches féministe: L'Action Thématique Programmée du CNRS. Les Cahiers du CEDREF, n. 10, p. 2001.

SCAVONE, Lucila. Estudos de Gênero e feministas: um campo científico. In Seminário: Gênero, multiculturalismo e direitos humanos IBEU/UNICAMP, 2011.

Recebido em 24 de julho de 2017. Aprovado em 23 de agosto de 2017. 